\title{
DISCLAIMER
}

This report was prepared as an account of work sponsored by an agency of the United States Government. Neither the United States Government nor any agency thereof, nor any of their employees, makes any warranty, express or implied, or assumes any legal liability or responsibility for the accuracy, completeness, or usefulness of any information, apparatus, product, or process disclosed, or represents that its use would not infringe privately owned rights. Reference herein to any specific commercial product, process, or service by trade name, trademark, manufacturer, or otherwise does not necessarily constitute or imply its endorsement, recommendation, or favoring by the United States Government or any agency thereof. The views and opinions of authors expressed herein do not necessarily state or reflect those of the United States Government or any agency thereof.
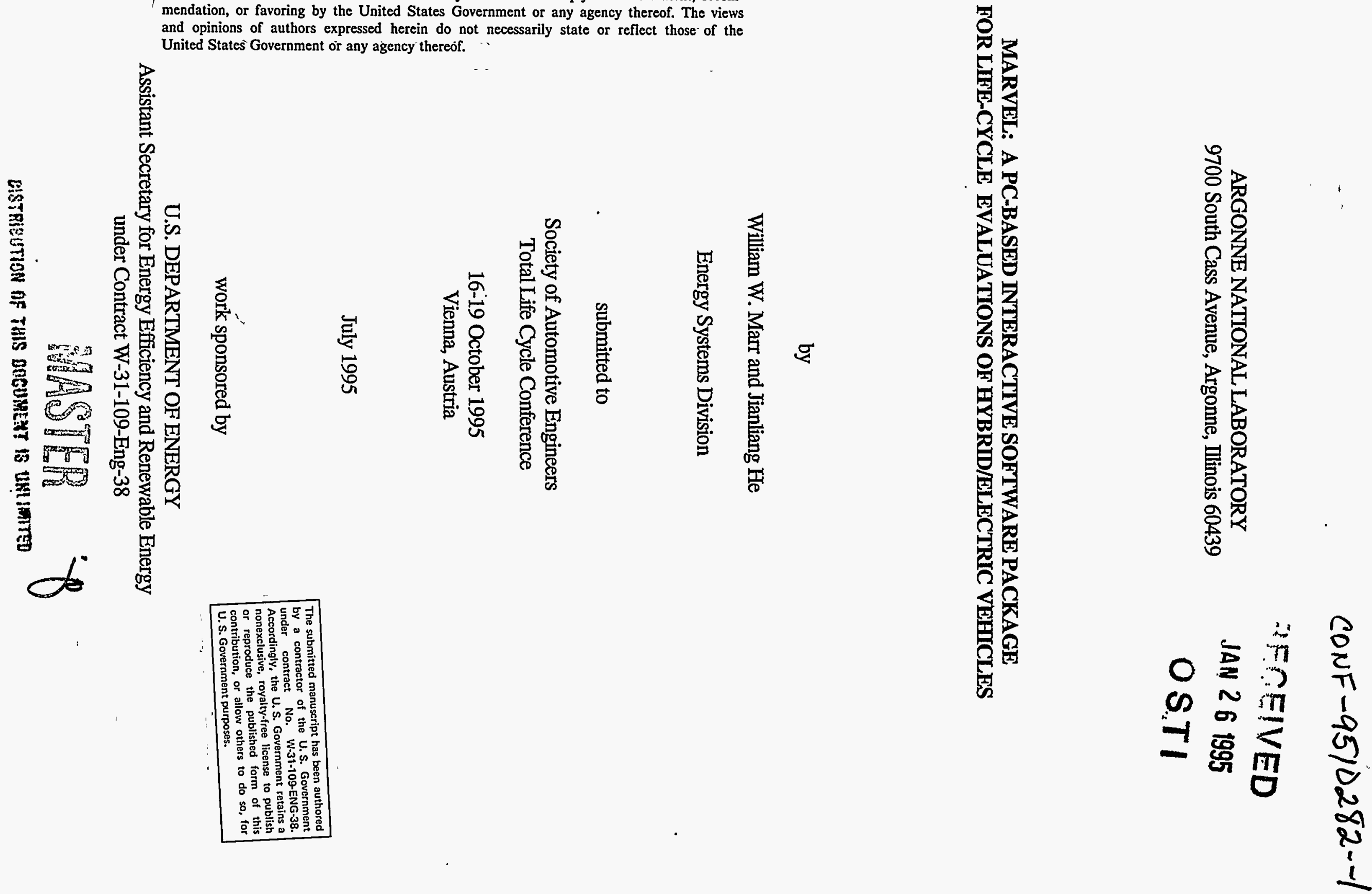


\section{MARVEL: A PC-Based Interactive Software Package for Life-Cycle Evaluations of Hybrid/Electric Vehicles}

William W. Marr and Jianliang He Argonne National Laboratory

1995 Total Life Cycle Conference \& Exposition October 16-19, 1995

Vienna, Austria 


\begin{abstract}
As a life-cycle analysis tool, MARVEL has been developed for the evaluation of hybrid/electric vehicle systems. It can identify the optimal combination of battery and heat engine characteristics for different vehicle types and performance requirements, on the basis of either life-cycle cost or fuel efficiency. Battery models that allow trade-offs between specific power and specific energy, between cycle life and depth of discharge, between peak power and depth of discharge, and between other parameters, are included in the software. A parallel hybrid configuration, using an internal combustion engine and a battery as the power sources, can be simulated with a user-specified energy management strategy. The PC-based software package can also be used for cost or fuel efficiency comparisons among conventional, electric, and hybrid vehicles.
\end{abstract}

\section{INTRODUCTION}

Recent environmental pressures to improve ambient air quality have renewed interest in the research and development of hybrid/electric vehicles (HEVs). Various systems bave been proposed and assessed. Yet seldom have the assessments included a comprehensive cost evaluation. Since cost competitiveness is one of the key factors in determining the marketability of any vehicle system, it is imperative to have some means of evaluating the life cycle cost of a design so that the initial cost of the vehicle and its operating and maintenance costs are considered.

Argonne National Laboratory (ANL) has been a participant in the HEV research and development program of the U.S. Department of Energy (DOE) for the past several years. MARVEL is one of the computer software packages developed at ANL for the analysis of HEV systems. It was originally written in PL/ language [1] and was later converted to FORTRAN. Several modifications and improvements, including an option for optimization based on fuel efficiency, were also made to the software.

The unique characteristics and design flexibility inherent in hybrid vehicles have made the analysis of these systems difficult. Of the many design variables (such as system configuration, energy management strategy, mode of operation, and types and sizes of the auxiliary power unit [APU]), the battery system is probably the most complex. For example, it is possible to trade certain battery characteristics for others to reach the best compromise for a given application. For a specific vehicle design and energy management strategy, a unique set of battery characteristics is best suited for the intended mission. MARVEL utilizes a methodology that identifies the combination of APU size and. battery characteristics that leads to the lowest life-cycle cost or the least energy consumption.

\section{MODEL DESCRIPTION}

The hybrid vehicle system modeled in MARVEL is that of a parallel configuration, consisting of an internal combustion engine (ICE) and a battery, as shown in Fig. 1. Depending on the energy management strategy employed, the power from the ICE can be used to propel the vehicle during periods of high-load demand and to recharge the battery during periods of low-load demand. The battery also accepts power generation from regenerative braking as long as the state-ofcharge of the battery allows.

BATTERY MODELING - Several battery relationships are modeled in MARVEL to allow trade-offs in the design process:

Specific Energy vs. Specific Power - This relationship, generally referred to as the Ragone curve, is the design tradeoff of specific energy and specific power.

$$
\bar{P}_{B}=a_{0} \bar{E}_{B}+\left(\frac{1}{3}-a_{0}\right) E_{3},
$$

where $\bar{P}_{\mathrm{B}}$ is the average specific power during discharge (W/kg); $\bar{E}_{\mathrm{B}}$ is the average specific energy during discharge $(\mathrm{Wh} / \mathrm{kg}) ; E_{3}$ is the specific energy at the 3 -h discharge 
rate $(\mathrm{Wh} / \mathrm{kg})$; and $a_{0}$ is the slope of the Ragone curve.

Peak Power vs. Specific Energy and DOD - Peak power capability of certain batteries deteriorates considerably during deep discharges, and the maximum allowable depth-ofdischarge (DOD) can become an important design parameter. In MARVEL, peak power of a battery is assumed to be related to its specific energy and DOD by the following equation:

$$
P_{B}=\left(a_{1}+a_{2} \times D O D\right) E_{3}+a_{3},
$$

where $P_{B}$ is the peak specific power $(W / \mathrm{kg}) ; D O D$ is the fractional depth of discharge; and $a_{1}, a_{2}$, and $a_{3}$ are battery coefficients.

Cycle Life vs. DOD - The trade-off between cycle life and DOD can be an important design consideration, especially for those batteries that exhibit the characteristics of a shortened cycle life due to peak power pulses at deep discharge. MARVEL uses a modified version of the heuristic equation proposed by Seiger [2] to describe the relationship between cycle life and DOD.

$$
L_{B}=L_{B 0} e^{\alpha(1-D O D)},
$$

where $L_{B}$ is the battery life capability in cycles for a given DOD; $L_{B O}$ is the battery life in cycles at $100 \%$ DOD; and $\alpha$ is a battery constant.

Effects of battery size - Battery size ( $\mathrm{kWh})$, is an important but frequently ignored factor that influences specific energy, specific power, and cost. Certain battery types (such as flow batteries and high-temperature batteries) do not scale down well with battery performance, falling off rapidly below a certain size. Battery scale factors are input as functions of $\mathrm{kWh}$.

ICE MODELING - Engine performance data are input in tabular form. Engine speed is related to vehicle speed by a user-specified gear-shift schedule. For an engine with a size that is different from that of the input base engine, performance is assumed to be directly proportional to the base engine.
VEHICLE MODELING - Analysis of a HEV requires the modeling of the vehicular system. The following vehicle weight equations are used in MARVEL:

$W_{T}=\frac{W_{P L}+W_{B D}+W_{D}+W_{F}+W_{M}+W_{I}}{1-\beta_{B}}$,

and

$$
\bar{W}_{\mathrm{T}}=W_{T^{-}}(1-\Gamma) W_{P L},
$$

where $W_{T}=$ gross vehicle weight; $\bar{W}_{\mathrm{T}}=$ average vehicle weight; $W_{P L}=$ payload of vehicle; $W_{B D}=$ weight of vehicle body; $W_{D}=$ weight of drivetrain; $W_{F}=$ weight of frame (chassis); $W_{M}=$ weight of motor and controller; $W_{l}=$ weight of ICE; $\beta_{B}=$ weight fraction of battery (defined as battery weight over gross vehicle weight); and $\Gamma=$ average fractional payioad on board.

The weights of body and chassis are assumed to vary with battery compartment volume and engine volume. The weights of other components are functions of the power requirements of the individual components or of the vehicle.

ENERGY MANAGEMENT STRATEGIES - Several energy management strategies are available in MARVEL for analyzing a hybrid vehicle. Either the battery or the ICE can . be used as the primary source of power. For example, in the case of the so-called dual-peaking strategy, the battery provides the primary source of power as long as its DOD is below a predetermined value. In this mode of operation, the ICE is used as the peaking device whenever the power requirement of the vehicle exceeds the battery power capability. After the battery energy is depleted such that its DOD reaches the predetermined value, the ICE takes over and acts as the primary power source. The battery then provides the necessary peaking power upon demand. In this mode of operation, the ICE also charges the battery whenever it has power to spare.

COST MODELING - Costs of individual components are, in general, expressed as a combination of a fixed cost and a variable cost. All costs are in dollars of initial year when the vehicle is purchased. Replacement costs and operating/maintenance costs are subject to a constant cost escalation rate and are discounted to the initial year for computing the life-cycle cost. 
Battery - Battery and vehicle analysts have traditionally considered battery cost as a single fixed value (i.e., $\$ \mathbf{k W h}$ ). However, battery cost is actually quite variable, given the tradeoffs among cost, energy, and power that are available to the designer. MARVEL uses an equation derived by Symons [3]:

$$
C_{B}=C_{B I}+C_{B e} E_{T}+C_{B p} P_{T},
$$

where $C_{B l}=$ battery fixed cost (\$); $C_{B e}=$ battery energy cost (\$/kWh); $C_{B p}=$ battery power cost $(\$ / \mathrm{kW}) ; E_{T}=$ battery total energy $(\mathrm{kWh})$; and $P_{T}=$ battery total power $(\mathrm{kW})$.

Vehicle Components - Costs of components, except that of the battery, are expressed as the combination of a fixed cost and a variable cost. The variable cost of a component is a function of either its weight or, in the case of a power-transmitting component, its power rating.

The total first cost of the vehicle is the sum of the individual costs of the chassis, drivetrain, body, tires, ICE, motor and controller, and the initial set of batteries. Dealer markup is included in the first cost of the vehicle, whereas manufacturer markup only is assumed for the replacement of batteries and tires. In addition to these costs, the total life-cycle cost also includes such operating costs as fuel (gasoline and electricity), repair and maintenance, and disposal costs (or salvage values) of both the batteries and the vehicle.

\section{CALCULATION PROCEDURE}

In the search for the optimal configuration for a given vehicle and mission (i.e., payload, $0-60 \mathrm{mph}$ acceleration, top speed, hill climbing, maximum range, and driving cycle), MARVEL iterates on ICE size (HP), battery weight fraction $\left(\beta_{B}\right)$, and maximum allowable $D O D$, with the bounds specified by the user. For a given HP, and over the entire range of $\beta_{B}$ and DOD, results corresponding to the set of battery parameters that yield the least life-cycle cost (or best fuel efficiency) and satisfying, at the same time, the energy strategy and system constraints are saved. If a design (i.e., combination of HP, $\beta_{B}$, and DOD) does not satisfy the constraints, no results are saved, and a message is displayed to inform the user that there is no physical results for this HP. The program then proceeds to the next higher HP, finds the best results, and compares them with the previous results, always saving the optimal results. This process continues until the upper bound of the HP is reached. At this point, MARVEL terminates the calculations and prints out the optimal results.

\section{INPUT DESCRIPTION}

Inputs to MARVEL are grouped into three separate data sets: one for the vehicle, one for the driving cycle, and one for the battery. Users can use their own input data sets or modify existing default data sets. Certain preselected parameters can also be changed interactively.

Vehicle - Input data include weight and cost parameters for each component, vehicle life, trip characteristics (e.g., driving distance and trip distribution), vehicle characteristics (e.g., drag coefficient, frontal area, rolling resistance), efficiencies (e.g., driveline, motor/generator, battery charger, - regenerative braking), performance requirements (e.g., 0-60 $\mathrm{mph}$ acceleration time, top speed, grade, maximum range and payload), and the lower and upper bounds of the ICE size searched. Several default vehicle data sets are included in the software package. These include the Eaton Dual-Shaft Electric Propulsion Van (DSEP), the Improved DSEP (IDSEP), the Ford Second-Generation Single-Shaft Electric Propulsion System (ETX-II), the General Motors G-Van and Impact, and the Chrysler TEVan.

- Driving Cycle - Several default driving cycles in the form of speed-time sequences are included in the MARVEL software package. These include the Federal Urban Driving Schedule (FUDS) [4], the Federal Highway Driving Cycle [5], the New York City Driving Cycle (NYCC) [6], LA-92. [7], ECE-15 , Sydney and JAPAN-10 [8], and several constant speeds.

Battery - Parameters concerning battery cost, specific power and energy, cycle life, efficiency, scale factors, lower and upper bounds of $\beta_{B}$ and DOD, etc., are required as input.

Many default battery-technology data sets (e.g., lead-acid, sodium-sulfur, zinc-bromine, nickel-iron, nickel-cadmium, and nickel-metal hydride) are included in the software package.

\section{OUTPUT DESCRIPTION}

Output data available include vehicle peak power demand, average energy requirements (with and without regenerative braking), annual electricity and fuel consumptions, energy consumption at the primary source, battery weight fraction, maximum battery DOD allowed, weights and costs of the vehicle and its components, optimal battery design (specific energy, peak power, and weight), battery life, vehicle initial cost, and total life-cycle cost. An option is also available to print out second-by-second vehicle speed and power demand and, in the case of a hybrid vehicle, the power distribution according to the mode of operation during a driving cycle. 


\section{SAMPLE PROBLEM}

A sample problem is presented here to demonstrate the use of the MARVEL software package. A compact hybrid vehicle is optimized for two different driving cycles (i.e., the LA-92 and the ECE-15) on the basis of either life-cycle cost or fuel efficiency. Table 1 shows the characteristics of the vehicle and other data assumed for the sample problem. The Dual-Peaking energy management strategy included in the software package is employed. Engine characteristics similar to those of GM's 1984 1.8-L Pontiac production engine [9] are assumed. Different prices for gasoline and electricity are assumed for the LA-92 driving cycle (United States) and the ECE-15 driving cycle (Europe). The ICE sizes for both cases are optimized in the range of 20 and $60 \mathrm{hp}$ (14.9 and $44.7 \mathrm{~kW})$.

Table 2 shows some results of the analysis. For the LA-92 driving cycle, the optimal ICE size is closer to the upper boundary of the user-specified range, while for the ECE-15 driving cycle, the optimal ICE size is at the lower boundary. (These findings are based on the combined effects of driving pattern and energy prices.) Thus, from a market perspective, the model in this sample problem suggests that a conventional nonbattery-powered vehicle is more cost-effective in the United States, while a hybrid vehicle is more cost-effective in Europe. These findings are expected because gasoline prices in the United States are relatively low. In the United States, until gasoline prices go much higher, or hybrid component costs improve significantly compared with current values, hybrid vehicles cannot compete with conventional vehicles if life-cycle cost is the only consideration. The analysis also shows that, for the cases considered, the model's suggested design values for vehicle and battery characteristics are quite similar whether the vehicle system is optimized on the basis of life-cycle cost or fuel efficiency, because performance constraints dominate the design.

\section{SUMMARY AND COMMENTS}

MARVEL is a user-friendly, interactive PC-based software package that can be used to analyze ICE/battery hybrid vehicle systems. The extensive modeling of interrelationships among battery characteristics included in the software package enables trade-offs to be made to arrive at an optimal design configuration. Currenly, the opimization is based on either the life-cycle cost or the fuel efficiency. Future improvements might include an option that allows users to choose emissions as a design criterion.

\section{REFERENCES}

1. Marr, W.W., and W.J. Walsh, Life-Cycle Cost Evaluation of Electric/Hybrid Vehicle, Energy Conversions and Management, Vol. 33, No. 9, pp. 849-853 (1992).
2. Seiger, H.N., Effects of Depth of Discharge on Cycle Life of Near-Term Batteries, Proc. 165th IECEC Conf. 819064 (1981).

3. Symons, P.C., Cost-Effective Goals for EV Battery Research: Functional Relationship of Battery Weight and Cost, Extended Abstract No. 5, 162nd Meeting of the ECS, Detroit Mich. (September 1982).

4. Environment Reporter, EPA Urban Dynamometer Driving Schedule for Light-Duty Vehicles, Light-Duty Trucks, and Motorcycles with Engine Displacements Equal to or Greater than $170 \mathrm{cc}(10.4 \mathrm{cu}$. in.), Federal Regulations, 128, p. 2114 (1992).

5. Environment Reporter, Highway Fuel Economy Driving Schedule (Applicable to 1978 and Later Model Year Automobiles), Federal Regulations, 128, p. 4040 (1994).

6. Environment Reporter, EPA New York City Cycle for Light-Duty Vehicles and Light-Duty Trucks, Federal Regulations, 128, p. 2132 (1993).

7. Austin, T.C., et al., An Analysis of Driving Patterns in Los Angeles during 1992, presented at the Third Annual CRC-APRAC On-Road Vehicle Emissions Workshop, (Dec. 3, 1992).

8. Milkins, E., and H. Watson, Comparison of Urban Driving Patterns, Society of Automotive Engineers Paper No. 830939, Warrendale, Penn. (1983).

9. Hefner, F.E., General Motors Research Laboratories, Warren, Mich., personal communication (November 1984).

10. Wang, Q., and M..A. Deluchi, Impact of Electric Vehicles on Primary Energy Consumption and Petroleum Displacement, Energy, Vol. 17, No. 4, pp. 351-366 (1992).

\section{ACKNOWLEDGMENTS}

The authors wish to thank Dr. Dan Santini, Center for Transportation Research, Argonne National Laboratory, for his continuing interest and support of this work; Mr. Roy Cuenca, also of Argonne, for providing some of the data used in the sample problem; and Dr. Phil Patterson, project officer, U.S. Department of Energy, for support of the "Transportation Projection and Assessment" research project under which this work has been conducted. The work reported here was sponsored by the U.S. Department of Energy, Assistant Secretary for Energy Efficiency and Renewable Energy, under contract W-31-109-Eng-38. 
Table 1 Selected Data Assumed for Sample Problem

\begin{tabular}{|c|c|}
\hline Drag Coefficient & 0.22 \\
\hline Frontal Area, $\mathrm{m}^{2}$ & 1.8 \\
\hline Rolling Resistance & 0.005 \\
\hline Driveline Efficiency, \% & 90 \\
\hline Motor/Generator Efficincy, \% & 90 \\
\hline Charger Efficiency, \% & 87.5 \\
\hline Regenerative Braking, Eff., \% & 50 \\
\hline Acceleration $0-96 \mathrm{kmph}, \mathrm{s}$ & 13 \\
\hline Top Speed, kmph & 120 \\
\hline Grade, \% & 0.0 \\
\hline Max. Electric Only Range, km & 120 \\
\hline Average Daily Range, km & 88 \\
\hline Annual Mileage, km & 22890 \\
\hline Payload, kg & 136 \\
\hline Vehicle Life, yr & 12 \\
\hline Vehicle Use, days/yr & 260 \\
\hline Annual Interest Rate, \% & 6.5 \\
\hline Annual Price Escalation, \% & 1.0 \\
\hline Electricity Rate, $\$ / \mathrm{kWh}$ & $\begin{array}{l}0.06(L A-92) ; \\
0.15 \text { (ECE-15) }\end{array}$ \\
\hline Gasoline Price, \$/Gallon & $\begin{array}{l}1.5(\mathrm{LA}-92) \\
6.0(\mathrm{ECE}-15)\end{array}$ \\
\hline $\begin{array}{l}\text { Battery State-of-Art Specific } \\
\text { Energy @C/3,Wh/kg }\end{array}$ & 45 \\
\hline Battery Specific Power, W/kg & $\begin{array}{l}165 @ 50 \% \mathrm{DOD} \\
150 @ 80 \% \mathrm{DOD}^{*}\end{array}$ \\
\hline $\begin{array}{l}\text { Battery State-of-Art Specific } \\
\text { Power, W/kg }\end{array}$ & 158@80\%DOD \\
\hline Battery Fixed Cost, $C_{B 1}, \$$ & 500 \\
\hline Battery Energy Cost, $C_{B e} \$ / k W h$ & 96 \\
\hline Battery Power Cost, $C_{\mathrm{Bp}}, \$ / \mathrm{kW}$ & 18 \\
\hline BatteryLife@100\%DOD, cycles & 280 \\
\hline Battery Efficiency, \% & 78 \\
\hline
\end{tabular}

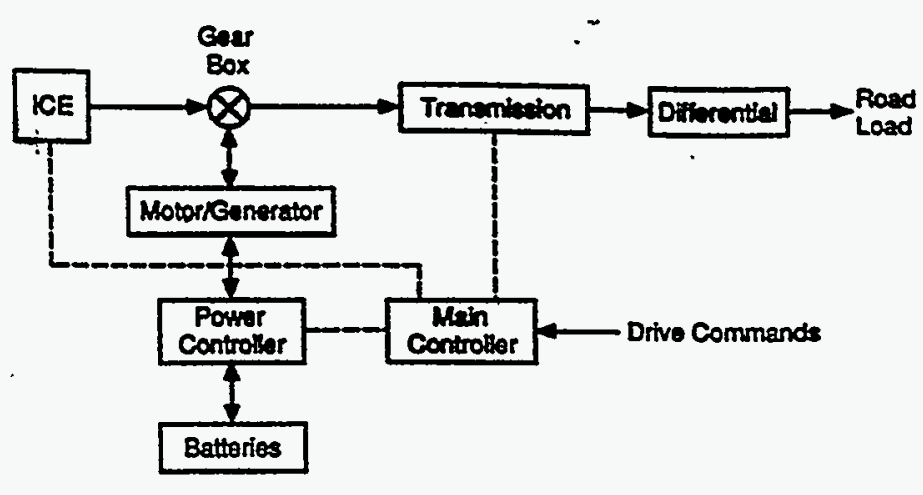

Fig. 1 A Parallel Configuration in MARVEL

- At C/3 specific energy of $45 \mathrm{Wh} / \mathrm{kg}$. Many other values for the components are specified as inputs to the models but are not listed here. 
Table 2. Results for Sample Problem

\begin{tabular}{|c|c|c|c|c|}
\hline \multirow{2}{*}{$\begin{array}{l}\text { Driving Cycle } \\
\text { Optimization } \\
\text { Criterion }\end{array}$} & \multicolumn{2}{|c|}{ LA-92 } & \multicolumn{2}{|c|}{ ECE-15 } \\
\hline & Life-Cycle Cost & Fuel Efficiency & Life-Cycle Cost & Fuel Efficiency \\
\hline ICE Size, kW & 44.7 & 41.0 & 14.9 & 14.9 \\
\hline Battery Wt., kg & 254 & 254 & 250 & 144 \\
\hline $\begin{array}{l}\text { Battery Specific Energy } \\
@ C / 3 \text { Rate, Wh/kg }\end{array}$ & 150 & 155 & 150 & 150 \\
\hline $\begin{array}{l}\text { Battery Specific Power } \\
@ 80 \% \text { DOD, W/kg }\end{array}$ & 45.0 & 41.5 & 45.0 & 45.0 \\
\hline Battery kWh@C/3 Rate & 11.4 & 10.5 & 11.3 & 6.49 \\
\hline Battery kW@80\%DOD & 38.1 & 39.5 & 37.5 & 21.6 \\
\hline Battery Max. DOD, \% & 60 & 60 & 65 & 100 \\
\hline Battery Ave. DOD, \% & 44 & 44 & 47.7 & 73.4 \\
\hline Battery Life, cycle (yr) & $1015(3.9)$ & $1015(3.9)$ & $932(3.6)$ & $517(2.0)$ \\
\hline Motor Capacity, kW & 33.9 & 37.6 & 48.0 & 43.8 \\
\hline Gross Vehicle Wt., kg & 1587 & 1587 & 1565 & 1442 \\
\hline $\begin{array}{l}\text { Ave. Energy requirement @ } \\
\text { wheels" } \mathrm{Wh} / \mathrm{km} \text {-kg }\end{array}$ & 0.059 & 0.059 & 0.04 & 0.04 \\
\hline $\begin{array}{l}\text { Peak Power Demand @ } \\
\text { wheels, W/kg }\end{array}$ & 32.0 & 32.0 & 32.3 & 32.3 \\
\hline Vehicle Cost, $\$$ & 15431 & 15472 & 15080 & 13889 \\
\hline Initial Battery Cost, \$ & 2282 & 2222 & 2257 & 1512 \\
\hline Replacement Battery Cost, \$ & 4040 & 3934 & 4501 & 6577 \\
\hline $\begin{array}{l}\text { Annual Electricity } \\
\text { Consumption, } \mathrm{kWh}\end{array}$ & 2612 & 2408 & 2695 & 2472 \\
\hline $\begin{array}{l}\text { Annual Gasoline } \\
\text { Consumption, gal }\end{array}$ & 169 & 180 & 54 & 60 \\
\hline Annual Energy Costs, \$ & 410 & 414 & 728 & 731 \\
\hline $\begin{array}{l}\text { Fuel Efficiency @ Primary } \\
\text { Source,, Btu/mile }\end{array}$ & 3723 & $\begin{array}{l}3664 \\
y\end{array}$ & 2675 & 2556 \\
\hline Life-Cycle Cost, $\$ / \mathrm{km}$ & 0.143 & 0.144 & 0.159 & 0.163 \\
\hline
\end{tabular}

* Assumed primary energy sources (overall efficiency for energy production processes, \%) [10]:

Petroleum to gasoline (83.1)

Coal to electricity (29.9)

* Including energy recovery from regenerative braking 